\title{
Eradication of Helicobacter Pylori: In Search of a Better Therapy
}

\section{Marco Manfredi ${ }^{1 *}$, and Gian Luigi de'Angelis ${ }^{2}$}

${ }^{1}$ Department of Medicine, Sant'Anna Hospital, Reggio Emilia, Italy

${ }^{2}$ Pediatrics Department, University of Parma, Parma, Italy

From the moment Helicobacter pylori was discovered in 1982, gastroenterologists realized that it is not a common bacterial infection. And in fact, various changes have had to be made to therapeutic approaches in an attempt to eradicate it [1].

Unlike more common infections, for which we usually have a wide range of treatment options, $H$. pylori is sensitive to only a few medications, and their widespread use (and, sometimes, abuse) in fighting infections, particularly in the respiratory tract, has led to a reduction in their effectiveness against this bacterium [1]. The situation is exacerbated by the fact that $H$. pylori itself generates pharmacological resistance that differs with geographic area and also compromises successive second and third-line therapies. [2-4]. What's more, $H$. pylori have a number of properties that are highly peculiar and perhaps unique. First of all, it lives in the stomach, an unusual environment (before $H$. pylori was discovered, it was thought that the stomach was a sterile environment which could not host pathogens). Also, since $H$. Pylori is found inside the gastric epithelial cells, it is harder to reach with concentrations of medication that are high enough to effect elimination [5].

In the late 1980s and early 1990s, a triple therapy was widely used that combined ranitidine with antibiotics with or without bismuth $[6,7]$. Subsequently, the usefulness of PPIs was recognized not only to reduce gastric acidity to a greater degree than ranitidine, thus creating an environment that is less favourable to $H$. pylori growth, but also to damage $H$. pylori itself [8], which has proton pumps that are similar to those found in humans [9]. After it was established that an antibiotic alone was insufficient for obtaining an adequate eradication rate, a standard triple therapy (PPI + two antibiotics) began to be administered [10-12]. This has been the most widely used treatment for at least two decades. Over the years, studies have been carried out with different combinations of antibiotics (PPI with amoxicillin + clarithromycin or amoxicillin + metronidazole or clarithromycin + metronidazole) [1] The standard triple therapy no longer has acceptable eradication rates (74-78\%), since the rate of optimum effectiveness for an antibiotic is considered to be at least $80 \%$; however, the triple therapy is still the recommended first-line treatment in major international guide lines (European, American, Asiatic) [1, 13-15].

The eradication rates do not vary significantly with duration of therapy $(7,10$ or 14 days), but it must also be remembered that the longer the therapy is continued, the greater the side effects $[1,16]$. In all probability, the effectiveness of the triple therapy was due not only to the infrequent resistance of $H$. pylori to amoxicillin (which is the reason why this antibiotic is used in almost all eradicating treatments around the world), but also because this therapy began to be used many years ago, when resistance to clarithromycin and metronidazole was much lower than it is today [2,4]. Over the past few decades, the excessive use of antibiotics - especially to treat infections of the respiratory tract - has evidently reduced the effectiveness of the triple therapy.

Many studies have evaluated other therapeutic regimens using various durations of therapy, combinations of medications and numbers of antibiotics (dual-therapy, sequential, quadruple with or without bismuth, ...) [17-22].
Perhaps the most innovative therapy is still the sequential regimen $[23,24]$. A number of recent studies and meta-analyses have confirmed that this treatment is very effective, even in cases that are resistant to clarithromycin and imidazoles. As is true for virtually all eradicating therapies, the key antibiotic is amoxicillin administered during the first 5 days of therapy, which is able to weaken the H. pylori bacteria wall and prevent the formation of so-called clarithromycin efflux channels perhaps the major cause of the ineffectiveness of this antibiotic [25-27].

The greatest detractors of sequential therapy maintain that the sequentiality of the drugs itself (the fundamental therapeutic action) makes it difficult to take the antibiotics with precision, which ultimately has a negative effect on effectiveness. However, it has been shown that in clinical practice, patients who are non-compliant with regard to taking drugs are no different from those who take the triple therapy [28].

Given the ever increasing resistance to clarithromycin, studies on changing the sequence have recently been completed; that is, quinolones and rifabutin are used instead of clarithromycin. However, the results have been mixed $[29,30]$.

Subsequently, several authors began to evaluate the therapeutic effectiveness of using as first-line treatment the antibiotics that are normally allocated to the second or third therapeutic choice. The authors banked on the fact that if these antibiotics are effective in patients who have already been subjected to multiple eradicating therapies, then, a fortiori, they will be effective when used as first-line therapy (triple therapy with quinolones, with rifabutin...) [31-33]. Unfortunately, although a good initial result was obtained with drugs normally used as second and third-line therapy, they did not meet expectations of clearly increasing the percentage of eradication and did not solve the problem of antibiotic resistance; for example, quinolones generate resistance very quickly, but the best results are obtained by extending therapy for 14 days. Also, these drugs are expensive. As a result, they are now considered to be better as second-line choices. Rifampicin is saddled with rather serious side effects (such as melotoxicity) [31-35].

A therapeutic plan has recently been developed that involves quadruple therapy with omeprazole plus a single capsule containing three antibiotics (bismuth subcitrate, metronidazole and tetracycline) for ten days, which resulted in a good eradication rate (92-93\% ) [36] that improved to excellent $(97.1 \%$ ) when therapy was prolonged for two weeks [37]. This format offers the advantages of taking three antibiotics

*Corresponding author: Marco Manfredi, Department of Medicine, AUSL of Reggio Emilia, Sant'Anna Hospital, Castelnovo ne'Monti, Reggio Emilia, Italy, E-mail: marco.manfredi8@gmail.com

Received December 18, 2012; Accepted December 19, 2012; Published December 22, 2012

Citation: Manfredi M, de'Angelis GL (2013) Eradication of Helicobacter Pylori: In Search of a Better Therapy. Clin Microbial 1: e101. doi:10.4172/2327-5073.1000e101

Copyright: (c) 2013 Manfredi M, et al. This is an open-access article distributed under the terms of the Creative Commons Attribution License, which permits unrestricted use, distribution, and reproduction in any medium, provided the original author and source are credited. 
in a single capsule and overcoming resistance to metronidazole. The side effects seem to be similar to those of the standard triple therapy.

Even though bismuth is not widely available, quadruple therapy containing it is regaining significant popularity after being abandoned for some time due to the appearance of resistance.

This therapy is effective if prolonged for 14 days, but is perhaps the therapeutic scheme with the greatest risk of side effects $[1,38]$.

Over the past few years, the addition of adjuvants - i.e. natural substances known for their infection-fighting properties as well as for their general benefits to human health has begun to be evaluated, especially in an attempt to reduce the side effects associated with multiple antibiotic therapies. In various meta-analyses, the use of adjuvant has been shown to be effective not only for improving compliance, but also for raising eradication rates. The best adjuvant appears to be lactobacilli and bifidobacteria. Besides reducing the side effects of triple therapy, their bacteriocins weaken $H$. pylori by lowering the intragastric microbe level, which enhances the action of the antibiotics $[39,40]$. One of our studies has shown that the use of adjuvants (lactoferrin and probiotics) together with sequential therapy does not increase its already high eradication rate, but clearly alleviates its side effects, thus providing patients with better quality of life (we did not obtain additional improvements in compliance when lactoferrin was added to probiotics) [41].

Other studies have also investigated the effect of natural substances (such as olive oil and chewing gum) on H. pylori microbial load and confirmed that, in any case, various materials in nature may have infection-fighting properties but are perhaps difficult to standardize in clinical practice $[42,43]$.

According to one of the greatest international experts on $H$. pylori, the therapy of choice should be the one that offers the highest eradication rate and thus produces the smallest proportion of patients requiring repetition of treatment [44]. Treatment failure not only increases the percentage of second-line therapies, but also raises the expense of treatment and the percentage of patients who are lost at follow up. Thus, according to Graham, if a choice must be made between two therapies, it is illogical and unethical to advise using the one with the lower eradication rate as the initial therapy [45]. The purpose of anti-H. Pylori therapy should be to treat all patients with therapies that offer at least a $90 \%$ eradication rate (and preferably $95 \%$ or higher). The best locally available therapy should be used both as the first-line and the second-line treatment. After a therapy (such as sequential or concomitant) containing clarithromycin has failed, the best current therapy is the quadruple treatment with bismuth (where available) or the fluoroquinolone-containing triple therapy, which is optimally administered for at least 14 days. Levofloxacin should be avoided in areas with known resistance to this antibiotic $[33,45]$.

However, all things considered, the variable that best facilitates eradication is still antibiotic sensitivity [46], so perhaps the most advantageous therapeutic approach is the so-called tailored therapy based on a culture examination of biopsied gastric tissue (all infectious diseases should be subjected to treatment based on culture examination and antibiotic sensitivity). Alternatively, therapy based on local antibiotic resistance is still an option [47].

Some ten years ago, our group showed that treating a group of children with the tailored therapy led to very high eradication rates [48]. Other studies have confirmed the high eradication rate using treatments based on antibiotic sensitivity [49-51].
We agree with the recommendations of Graham, who advises making local adaptations to suit the different generic sensitivities to antibiotics, which in any case vary not only from country to country, but also between different areas in the same country. With tailored therapy, the latter principle is followed in any case, and personalized therapeutic schemes can also be offered. Smaller doses of antibiotics could be tried that are adequate to ensure the various MICs, in an attempt to reduce resistance and side effects. The disadvantage to this approach is the relative difficulty of obtaining a culture of $H$. pylori (a percentage of patients must be treated empirically in any case) and the limited availability of this method. The high cost of a culture examination could be offset by the higher eradication rate and consequent reduced need to repeat multiple therapeutic cycles.

Finally, since all antibiotic therapies generate unpleasant (but usually not serious) side effects, we believe that the combination with probiotics helps the patient withstand therapy which, even if it is personalized according to the antibiogram, may easily result in unpleasant ailments (especially of the gastrointestinal tract), because it consists of multiple drugs.

\section{References}

1. Malfertheiner P, Megraud F, O'Morain CA, Atherton J, Axon AT, et al. (2012) Management of Helicobacter pylori infection--the Maastricht IV/ Florence Consensus Report. Gut 61: 646-664.

2. Megraud F, Kist M, Lopez Brea M, Hirschl A, Andersen LP, Glupczynski Y Hirschl A Surveillance of Helicobacter pylori resistance to antibiotics in Europe 2008-2009. Gastroenterol 2011; 140(suppl.1):S312.

3. Kawai T, Yamagishi T, Yagi K, Kataoka M, Kawakami K, et al. (2008) Tailored eradication therapy based on fecal Helicobacter pylori clarithromycin sensitivities. J Gastroenterol Hepatol 23 Suppl 2: S171-174.

4. Tay CY, Windsor HM, Thirriot F, Lu W, Conway C, et al. (2012) Helicobacter pylori eradication in Western Australia using novel quadruple therapy combinations. Aliment Pharmacol Ther 36: 1076-1083.

5. Hazell SL, Lee A, Brady L, Hennessy W (1986) Campylobacter pyloridis and gastritis: association with intercellular spaces and adaptation to an environment of mucus as important factors in colonization of the gastric epithelium. J Infect Dis 153: 658-663.

6. Hentschel E, Brandstätter G, Dragosics B, Hirschl AM, Nemec H, et al. (1993) Effect of ranitidine and amoxicillin plus metronidazole on the eradication of Helicobacter pylori and the recurrence of duodenal ulcer. N Engl J Med 328: 308-312.

7. Graham DY, Lew GM, Ramirez FC, Genta RM, Klein PD, et al. (1993) Short report: a non-metronidazole triple therapy for eradication of Helicobacter pylori infection--tetracycline, amoxicillin, bismuth. Aliment Pharmacol Ther 7: 111-113.

8. Sachs G, Meyer-Rosberg K, Scott DR, Melchers K (1996) Acid, protons and Helicobacter pylori. Yale J Biol Med 69: 301-316.

9. Logan RP (1996) The chemotherapeutic effects of $\mathrm{H}+/ \mathrm{K}+$ inhibitors on Helicobacter pylori infection. Pharmacol Ther 69: 79-83.

10. Bayerdörffer E, Miehlke S, Mannes GA, Sommer A, Höchter W, et al. (1995) Double-blind trial of omeprazole and amoxicillin to cure Helicobacter pylor infection in patients with duodenal ulcers. Gastroenterology 108: 1412-1417.

11. Miehlke S, Mannes GA, Lehn N, Hele C, Stolte M, et al. (1997) An increasing dose of omeprazole combined with amoxycillin cures Helicobacter pylori infection more effectively. Aliment Pharmacol Ther 11: 323-329.

12. Lamouliatte H, Cayla R, Zerbib F, Forestier S, de Mascarel A, et al. (1998) Dual therapy using a double dose of lansoprazole with amoxicillin versus triple therapy using a double dose of lansoprazole, amoxicillin, and clarithromycin to eradicate Helicobacter pylori infection: results of a prospective randomized open study. Am J Gastroenterol 93: 1531-1534.

13. Egan BJ, Katicic M, O'Connor HJ, O'Morain CA Treatment of Helicobacter pylori Helicobacter 2007;12 (Suppl. 1):31-37.

14. Chey WD, Wong BC; Practice Parameters Committee of the American College of Gastroenterology (2007) American College of Gastroenterology guideline 
on the management of Helicobacter pylori infection. Am J Gastroenterol 102: 1808-1825.

15. Fock KM, Katelaris P, Sugano K, Ang TL, Hunt R, et al. (2009) Second AsiaPacific Consensus Guidelines for Helicobacter pylori infection. J Gastroentero Hepatol 24: 1587-1600

16. Vakil N, Megraud F (2007) Eradication therapy for Helicobacter pylori. Gastroenterology 133: 985-1001.

17. Graham DY, Lew GM, Malaty HM, Evans DG, Evans DJ Jr, et al. (1992) Factors influencing the eradication of Helicobacter pylori with triple therapy. Gastroenterology 102: 493-496

18. Houben MH, van de Beek D, Hensen EF, de Craen AJ, Rauws EA, et al. (1999) A systematic review of Helicobacter pylori eradication therapy--the impact of antimicrobial resistance on eradication rates. Aliment Pharmacol Ther 13: 1047-1055.

19. Wu DC, Hsu PI, Wu JY, Opekun AR, Kuo CH, et al. (2010) Sequential and concomitant therapy with four drugs is equally effective for eradication of $\mathrm{H}$ pylori infection. Clin Gastroenterol Hepatol 8: 36-41.

20. Park HK, Lee DH, Suh S, Seo PJ, Kim N, et al. (2011) Dual therapy trial using esomeprazole and amoxicillin as third-line rescue therapy for Helicobacter pylori infection. Clin Endosc 44: 33-37.

21. Laine L, Hunt R, El-Zimaity H, Nguyen B, Osato M, et al. (2003) Bismuthbased quadruple therapy using a single capsule of bismuth biskalcitrate metronidazole, and tetracycline given with omeprazole versus omeprazole, amoxicillin, and clarithromycin for eradication of Helicobacter pylori in duodenal ulcer patients: a prospective, randomized, multicenter, North American trial. Am J Gastroenterol 98: 562-567.

22. Manfredi M, Bizzarri B, de'Angelis GL (2012) Helicobacter pylori infection: sequential therapy followed by levofloxacin-containing triple therapy provides a good cumulative eradication rate. Helicobacter 17: 246-253.

23. Tong JL, Ran ZH, Shen J, Xiao SD (2009) Sequential therapy vs. standard triple therapies for Helicobacter pylori infection: a meta-analysis. J Clin Pharm Ther 34: 41-53

24. Jafri NS, Hornung CA, Howden CW (2008) Meta-analysis: sequential therapy appears superior to standard therapy for Helicobacter pylori infection in patients naive to treatment. Ann Intern Med 148: 923-931.

25. Zullo A, Hassan C, Cristofari F, Andriani A, De Francesco V, et al. (2010) Effects of Helicobacter pylori eradication on early stage gastric mucosa-associated lymphoid tissue lymphoma. Clin Gastroenterol Hepatol 8: 105-110.

26. Cole SP, Cirillo D, Kagnoff MF, Guiney DG, Eckmann L (1997) Coccoid and spiral Helicobacter pylori differ in their abilities to adhere to gastric epithelial cells and induce interleukin-8 secretion. Infect Immun 65: 843-846.

27. Benaissa M, Babin P, Quellard N, Pezennec L, Cenatiempo Y, et al. (1996) Changes in Helicobacter pylori ultrastructure and antigens during conversion from the bacillary to the coccoid form. Infect Immun 64: 2331-2335.

28. Nimish V (2007) New guidelines for Helicobacter pylori: applying them to your practice. Rev Gastroenterol Disord 7: 111-114.

29. Zullo A, De Francesco V, Hassan C, Ridola L, Repici A, et al. (2012) Modified sequential therapy regimens for Helicobacter pylori eradication: A systematic review. Dig Liver Dis 45: 18-22.

30. Qian J, Ye F, Zhang J, Yang YM, Tu HM, et al. (2012) Levofloxacin-containing triple and sequential therapy or standard sequential therapy as the first line treatment for Helicobacter pylori eradication in China. Helicobacter 17: 478485.

31. Gisbert JP (2009) Second-line rescue therapy of helicobacter pylori infection Therap Adv Gastroenterol 2: 331-356

32. Berning M, Krasz S, Miehlke S (2011) Should quinolones come first in Helicobacter pylori therapy? Therap Adv Gastroenterol 4: 103-114.

33. Miehlke S, Krasz S, Schneider-Brachert W, Kuhlisch E, Berning M, et al. (2011) Randomized trial on 14 versus 7 days of esomeprazole, moxifloxacin, and amoxicillin for second-line or rescue treatment of Helicobacter pylori infection. Helicobacter 16: 420-426.

34. Kuo CH, Kuo FC, Hu HM, Liu CJ, Wang SS, et al. (2012) The Optimal First-Line Therapy of Helicobacter pylori Infection in Year 2012. Gastroenterol Res Pract 2012: 168361
35. Wenzhen Y, Kehu Y, Bin M, Yumin L, Quanlin G, et al. (2009) Moxifloxacinbased triple therapy versus clarithromycin-based triple therapy for first-line treatment of Helicobacter pylori infection: a meta-analysis of randomized controlled trials. Intern Med 48: 2069-2076.

36. Malfertheiner P, Bazzoli F, Delchier JC, Celiñski K, Giguère M, et al. (2011) Helicobacter pylori eradication with a capsule containing bismuth subcitrate potassium, metronidazole, and tetracycline given with omeprazole versus clarithromycin-based triple therapy: a randomised, open-label, non-inferiority, phase 3 trial. Lancet 377: 905-913.

37. Salazar CO, Cardenas VM, Reddy RK, Dominguez DC, Snyder LK, et al. (2012) Greater than $95 \%$ success with 14-day bismuth quadruple anti- Helicobacte pylori therapy: a pilot study in US Hispanics. Helicobacter 17: 382-390.

38. Yoon JH, Baik GH, Kim YS, Suk KT, Shin WG, et al. (2012) Comparison of the Eradication Rate between 1- and 2-Week Bismuth-Containing Quadruple Rescue Therapies for Helicobacter pylori Eradication. Gut Liver 6: 434-439.

39. Lesbros-Pantoflickova D, Corthésy-Theulaz I, Blum AL (2007) Helicobacter pylori and probiotics. J Nutr 137: 812S-8S.

40. Gotteland M, Brunser O, Cruchet S (2006) Systematic review: are probiotics useful in controlling gastric colonization by Helicobacter pylori? Aliment Pharmacol Ther 23: 1077-1086.

41. Manfredi M, Bizzarri B, Sacchero RI, Maccari S, Calabrese L, et al. (2012) Helicobacter pylori infection in clinical practice: probiotics and a combination of probiotics + lactoferrin improve compliance, but not eradication, in sequential therapy. Helicobacter 17: 254-263.

42. Castro M, Romero C, de Castro A, Vargas J, Medina E, et al. (2012) Assessment of Helicobacter pylori eradication by virgin olive oil. Helicobacter 17: 305-311.

43. Dabos KJ, Sfika E, Vlatta LJ, Giannikopoulos G (2010) The effect of mastic gum on Helicobacter pylori: a randomized pilot study. Phytomedicine 17: 296-299.

44. Graham DY, Rimbara E Helicobacter pylori therapy in the west Japanese J Helicobacter Res 2012; 13: 4-9.

45. Graham DY, Calvet X (2012) Guide regarding choice of second-line therapy to obtain a high cumulative cure rate. Helicobacter 17: 243-245.

46. Tepes B, O'Connor A, Gisbert JP, O'Morain C (2012) Treatment of Helicobacter pylori infection 2012. Helicobacter 1: 36-42.

47. Graham DY, Shiotani A (2012) Which Therapy for Helicobacter pylori Infection? Gastroenterology.143: 10-20.

48. Street ME, Caruana P, Caffarelli C, Magliani W, Manfredi M, et al. (2001) Antibiotic resistance and antibiotic sensitivity based treatment in Helicobacte pylori infection: advantages and outcome. Arch Dis Child 84: 419-422.

49. Molina-Infante J, Pazos-Pacheco C, Vinagre-Rodriguez G, Perez-Gallardo B, Dueñas-Sadornil C, et al. (2012) Nonbismuth quadruple (concomitant) therapy: empirical and tailored efficacy versus standard triple therapy for clarithromycin-susceptible Helicobacter pylori and versus sequential therapy for clarithromycin-resistant strains. Helicobacter 17: 269-276.

50. Hsu PI, Wu DC, Wu JY, Graham DY (2011) Modified sequential Helicobacter pylori therapy: proton pump inhibitor and amoxicillin for 14 days with clarithromycin and metronidazole added as a quadruple (hybrid) therapy for the final 7 days. Helicobacter 16: 139-145.

51. Kawai T, Yamagishi T, Yagi K, Kataoka M, Kawakami K, et al. (2008) Tailored eradication therapy based on fecal Helicobacter pylori clarithromycin sensitivities. J Gastroenterol Hepatol 23 Suppl 2: S171-174. 